\title{
Gallbladder polyps between ultrasound and histopathology
}

\section{Abdel Rahman Al Manasra ${ }^{1}$, Haitham Qandeel ${ }^{2}$, Mohammad Al-Hurani ${ }^{1}$, Tagleb S Mazahreh ${ }^{1}$, and}

\section{Shadi Hamouri ${ }^{1}$}

1. Department of General Surgery, Faculty of Medicine, Jordan University of Science and Technology, Irbid, Jordan

2. Department of General Surgery, Faculty of Medicine, The Hashemite University, Zarqa, Jordan

\section{RESEARCH}

Please cite this paper as: Al manasra A, Qandeel $\mathrm{H}, \mathrm{Al}-$ Hurani M, Mazahreh T, Hamouri S. Gallbladder polyps between ultrasound and histopathology. AMJ 2018;11(1):37-41. https://doi.org/10.21767/AMJ.2017.3300

\section{Corresponding Author:}

Abdel Rahman Al Manasra M.D.

Department of Surgery,

Faculty of Medicine

Jordan University of Science and Technology

Irbid, P.O. Box 3030, Jordan

Email: abdjust@yahoo.com

\section{ABSTRACT}

\section{Background}

Gallbladder polyps (GBP) are rare. Ultrasound is the most widely used screening method for Gallbladder pathology.

\section{Aims}

We aim to analyse polyps identified in gallbladders removed by laparoscopy over a 14-year period, and to assess the ability of conventional ultrasound to differentiate GBPs from stones.

\section{Methods}

This is a retrospective study of 11,391 patients who underwent laparoscopic cholecystectomy from 2002-2016. Data concerning patients' characteristics, preoperative ultrasound findings, number and size of lesions, histologic features of polyps and gallbladder were collected.

\section{Results}

Forty-six patients had GBP(s) (0.4 per cent). Mean age was 54(range 17-85), 67.4 per cent were females. Body mass index (BMI) was 30 (range 19-43). GBP(s) were single in 63 per cent of cases. Polyp size ranged between 0.2 and $2.2 \mathrm{~cm}$ (average $1 \mathrm{~cm}$ ). Preoperative ultrasound successfully differentiated polyps from stones in nine cases (20 per cent). The most common histopathologic pattern was hyperplastic polyps in 18 cases (39.1), followed by cholesterol polyps (28.3 per cent), adenomyoma (13 per cent) and adenoma (8.7 per cent). The rest (10.9 per cent) were malignant polyps (adenocarcinoma). Polyps were associated with chronic cholecystitis in $40 / 46$ patients.

\section{Conclusion}

GBPs are rare. Hyperplastic polyps are the commonest in our region, probably due to chronic inflammation induced by gallstones. Although ultrasound seems to be sensitive to gallbladder lesions; its utility to differentiate polyps from stones is relatively low. Since one tenth of polyps were hiding malignancy, cholecystectomy is advised especially in elderly people.

\section{Key Words}

Gallbladder polyp, ultrasound, Jordan, cholecystitis

\section{What this study adds:}

\section{What is known about this subject?}

Gallbladder polyps (GBP) are rare and usually mistaken for gallstones by ultrasound.

\section{What new information is offered in this study?}

In areas where cholelithiasis is prevalent, hyperplastic polyps are more likely encountered than other types of GBPs, probably due to recurrent inflammation.

3. What are the implications for research, policy, or practice?

This study showed that one out of ten removed GBPs will be hiding malignancy, therefore, cholecystectomy is advised, especially in elderly patients.

\section{Background}

Gallbladder polyps are defined as outgrowths arising from 
the gallbladder mucosal wall, they are usually found incidentally on radiologic imaging or after cholecystectomy. ${ }^{1}$ Although most of these lesions are benign, the clinical significance of these lesions is related to their malignant potential and inability to exclude malignancy by imaging studies alone.

Christensen and Ishak described gallbladder polyps thoroughly in $1970 .^{1,2}$ They classified polyps as benign and malignant. ${ }^{3,4}$ Benign gallbladder polyps were further classified into pseudotumors, epithelial (adenomas) and mesenchymatous tumors. ${ }^{1}$

The exact incidence of gallbladder polyps is unknown. ${ }^{5}$ Multiple studies reported variable results; in one recent study by Park et al., ${ }^{6}$ a GBPs were identified histologically in 5.6 per cent to 6.9 per cent of removed gallbladders. In another study, by Matlok et al., ${ }^{7}$ a histologic prevalence of GBPs of 0.8 per cent was reported.

Different radiologic modalities were used to investigate $G B$ pathologies. Computed tomography (CT) scan was known to have unsatisfactory sensitivity for detecting gallbladder polyps -especially those less than $10 \mathrm{~mm}$ in diameter-, but with the advancement in CT technology, there was an increment in reported accuracy to detect GBPs and gallbladder polypoid carcinoma. ${ }^{1}$ Another modality, Magnetic resonance imaging (MRI), has not been widely used in diagnosis of gallbladder diseases, due to poor spatial and contrast resolution. ${ }^{8}$

On the other side, abdominal ultrasound has been widely utilized for diagnosis of gallbladder disease, likely secondary to its availability, low cost and sensitivity. The validity of preoperative ultrasound in detecting GBP has been assessed through correlation with histologic findings. The distinction between gallstones and polyps using ultrasound may be difficult especially when polyps are small in size $(<5 \mathrm{~mm}){ }^{1}$ In addition, ultrasound has a limited role in differentiation between benign and malignant polypoid lesions of the gallbladder. ${ }^{9}$

Our aim is to analyse polyps identified in gallbladders removed by laparoscopy, over a period of 14 years, and to assess ability to differentiate $\mathrm{GBP}(\mathrm{s})$ from stones utilizing conventional ultrasound.

\section{Method}

We did a retrospective study of 11,391 patients who underwent cholecystectomy from 2002-2016 at our institution. Forty-six patients were found to have GBPs.
Preoperative gallbladder ultrasound was done for all patients (LOGIQ E9, GE Healthcare, USA). Patient's anthropometric (weight, height and Body mass index (BMI)), demographic (age, gender), Clinical (Presentation and comorbidities), and radiological data were obtained. Histopathological features of polyps (number of polyps, size, classification and malignant transformation) and GBs were also reviewed by two pathologists. Patients' confidentiality was protected in accordance with declaration of Helsinki provisions. This study was approved by the King Abdullah university hospital ethics committee, reference number (477-2017).

Based on histopathology, we classified GBPs into benign and malignant polyps. Benign polyps included adenomas, adenomyomas, cholesterol, hyperplastic, inflammatory, and mesenchymal polyps (leiomyoma, fibroma, lipoma, etc.).

\section{Statistical analysis}

Data were described using means, percentages, and ranges wherever appropriate. Analysis was performed with the IBM SPSS v.20.0 (Chicago, IL, USA) software.

\section{Results}

Amongst the 11,391 patients underwent laparoscopic cholecystectomy, 46 (0.4 per cent) patients had GBPs. Table 1 summarizes patient's clinical and histopathologic (polyps) characteristics. Mean age was 54 (range 17-85), 67.4 per cent were females. Mean BMI was 30 (range 19-43). GBPs were single in 63 per cent of cases, and multiple in the rest. Polyps' sizes ranged from $0.2-2.2 \mathrm{~cm}$ (average $1 \mathrm{~cm}$ ). Preoperative ultrasound successfully differentiated polyps from stones in 9/46 cases (Sensitivity=19.5 per cent). The most common histopathologic pattern was hyperplastic polyps (Figure 1) in 18 cases (39.1), followed by cholesterol polyps (28.3 per cent), adenomyoma (13 per cent) and adenoma (8.7 per cent) (Figure 2). The rest (10.9 per cent) were Malignant polyps (adenocarcinoma). Polyps were associated with chronic cholecystitis in 40/46 patients. In patients with gallbladder adenocarcinoma, 3/5 were females, mean age was 58 years. Only one patient with cancer had chronic cholecystitis. No specific symptoms were observed in the cancer cases.

\section{Discussion}

The gallbladder polyp is rare entity, but its significance arises from the concern that it may be carcinoma of the gallbladder. The prevalence of gallbladder polyps ranges between $0.004-13.8$ per cent in removed gallbladders, ${ }^{10}$ and 1.5-4.5 per cent in gallbladders assessed by ultrasound. ${ }^{11,12}$ 
Multiple studies were carried out to identify risk factors for developing GBPs. Although several authors reported higher incidence of GBPs in men, ${ }^{9}$ most of them failed to identify a significant correlation between GBP formation and gender, or any of, obesity, age or co-morbidities. ${ }^{1,12}$ In our study, GBPs seemed to be more common in females (67.4 per cent) (F:M, 2:1) elderly (in 6th decade of life), and overweight individuals.

GBPs can be asymptomatic and found incidentally during abdominal imaging for other complaint, or associated with vague nonspecific or right upper quadrant abdominal pain. ${ }^{13,1}$ In our study, most patients presented with right upper quadrant pain, which could be attributed to the underlying chronic GB inflammation (cholecystitis) proved by histopathology in most cases (40/46 had chronic cholecystitis). The mechanism includes prolapse of the polyp into Hartmann's pouch, which may cause obstruction of the cystic duct leading to biliary colic and cholecystitis. $^{14,15}$

The classification of GBPs has been controversial. In 1970, Christensen and Ishak ${ }^{1}$, proposed their classification of GBPs based on histopathology. They divided Benign GBPs into: pseudotumors (cholesterol polyps, inflammatory polyps; cholesterolosis and hyperplastic), epithelial tumors (adenomas) and mesenchymatous tumors (fibroma, lipoma, and hemangioma). ${ }^{1}$ Multiple studies showed that among all types, cholesterol polyps are the most encountered, accounting for 60-90 per cent of all GBPs. ${ }^{1,16}$ Some studies linked obesity -evaluated by visceral and total adipose tissue- to the formation of cholesterol polyps in $\mathrm{GB} .{ }^{17}$ In our group of patients, most of GBPs that we examined were benign, and surprisingly, the commonest benign pattern was hyperplastic. This could likely be attributed to the inflammatory changes (cholecystitis) that may induce exaggerated mucosal response with hyperplasia.

Many studies investigated predictive factors of malignancy in a given gallbladder polyp. ${ }^{18}$ Some risk factors are related to the GBP itself (size, shape, and number of polyps), ${ }^{19}$ others are patient- related factors, similar to age, ethnicity, and diabetes mellitus. ${ }^{20,21}$ The most useful predictor for malignancy is found to be the size of the polyp. Studies usually support the assumption of malignancy in polyps larger than $2 \mathrm{~cm}$, until proven or excluded by histology, and the increased probability of malignancy in polyps $>10 \mathrm{~mm}$ in size. ${ }^{22,23}$ Some reports showed that small size GBPs can also be malignant, especially in Asian population. ${ }^{24}$ In our study, the average size of gallbladder polyp ranged between $0.2-2.2 \mathrm{~cm}$ (average $1 \mathrm{~cm}$ ) with 63 per cent of cases found to have single gallbladder polyp. All malignant polyps were $>2 \mathrm{~cm}$ in diameter, and 80 per cent (4/5) of patients with malignant polyps aged more than 60 years.

Ultrasound is still considered the ideal imaging study for gallbladder and biliary tree, ${ }^{7}$ with a reported sensitivity for gallbladder polyps of approximately 90.1 per cent, and specificity of 93.9 per cent, ${ }^{10}$ In one study by Akyürek, et al., ${ }^{25}$ the sensitivity and specificity of ultrasound for polyps was highly dependent on the polyp size, with a sensitivity of 20 per cent for polyps $<1 \mathrm{~cm}$, compared to 80 per cent for polyps $>1 \mathrm{~cm}$. Ultrasound sensitivity may be superior to other modalities like CT and MRI, ${ }^{5}$ despite of that, it seems to have high percentage of false positive diagnosis. ${ }^{7}$ Zielinski and colleagues revealed that 27 per cent of patients diagnosed with GBP by preoperative ultrasound did not have GBPs upon histopathologic analysis. ${ }^{26}$ In our study, ultrasound differentiated polyps in almost 20 per cent of cases. In general, the low ability to differentiate GBPs from stones utilizing ultrasound may be attributed to many factors including the operator experience (most of gallbladder ultrasounds are performed by residents), and technical challenges due to patients' body habitus. ${ }^{1}$

With the advancement in the medical field and the popularity of the ultrasound, there is an increment in the detection rate for GBPs. Some reports showed that visualization of the vascular supply to the GBP may be increased using a contrast-enhanced ultrasound. ${ }^{27}$ Moreover, when comparing the conventional ultrasound to the endoscopic ultrasound (EUS), several small studies showed the EUS is more accurate than conventional ultrasound in diagnosing GBPs, but no significant data conclude that EUS should be used instead of conventional ultrasound, ${ }^{21,28}$ especially with the wide availability and cost effectiveness of the conventional ultrasound.

Limitations of this study include; first, it was a retrospective, nonrandomized study. Second, the total number of patients with GBPs was small to conduct assessment for risk factors with statistical significance. In spite of these limitations, we analysed the histopathologic patterns of GBPs in our population with attention to polyps complicated by malignant transformation, and assessed the ability to differentiate GBPs from stones using the conventional ultrasound.

\section{Conclusion}

GBPs are rare. Hyperplastic polyps are the commonest in our region, probably due to chronic inflammation induced 
by gallstones. Although ultrasound seems to be sensitive to gallbladder lesions; its utility to differentiate polyps from stones is relatively low. Since one tenth of polyps were hiding malignancy, cholecystectomy is advised especially in elderly people.

\section{References}

1. Andrén-Sandberg $\AA$. Diagnosis and Management of gallbladder polyps. N Am J Med Sci. 2012;4(5):203-211. doi: 10.4103/1947-2714.95897

2. Christensen $A H$, Ishak KG. Benign tumors and pseudotumors of the gallbladder. Report of 180 cases. Arch Pathol. 1970;90:423-432.

3. Weedon D. Benign mucosal polyps. In: Pathology of the gallbladder, Mason, New York 1984. p.195.

4. Laitio M. Histogenesis of epithelial neoplasms of human gallbladder II. Classification of carcinoma on the basis of morphological features. Pathol Res Pract. 1983;178:5766.

5. Guo J, Wu G, Zhou Z. Polypoid lesions of the gallbladder: report of 160 cases with special reference to diagnosis and treatment in China. Int J Clin Exp Pathol. 2015;8(9):11569-11578.

6. Park KW, Kim SH, Choi SH, et al. Differentiation of nonneoplastic and neoplastic gall- bladder polyps $1 \mathrm{~cm}$ or bigger with multi-detector row computed tomography. J Comput Assist Tomogr. 2010;34:135-139.

7. Matłok M, Migaczewski M, Major $P$, et al. Laparoscopic cholecystectomy in the treatment of gallbladder polypoid lesions - 15 years of experience. Pol Przegl Chir. 2013;85(11):625-629.

8. Inui K, Yoshino J, Miyoshi H. Diagnosis of gallbladder tumors. Intern Med. 2011;50:1133-1136.

9. Matos AS, Baptista HN, Pinheiro C, et al. Gallbladder polyps: How should they be treated and when? Rev Assoc Med Bras. 2010;56:318-321.

10. Yang HL, Sun YG, Wang Z. Polypoid lesions of the gallbladder: diagnosis and indications for surgery. $\mathrm{Br} \mathrm{J}$ Surg. 1992;79:227.

11. Heyder N, Günter E, Giedl J, et al. Polypoid lesions of the gallbladder. Dtsch Med Wochenschr. 1990;115:243.

12. Jørgensen $\mathrm{T}$, Jensen $\mathrm{KH}$. Polyps in the gallbladder. A prevalence study. Scand J Gastroenterol. 1990;25:281.

13. Kwon W, Jang JY, Lee SE, et al. Clinicopathologic features of polypoid lesions of the gallbladder and risk factors of gallbladder cancer. J Korean Med Sci. 2009;24(3):481487.

14. McGregor JC, Cordiner JW. Papilloma of the gallbladder. Br J Surg. 1974;61:356.

15. Kane CF, Brown CH, Hoerr SO. Papilloma of the gallbladder; report of eight cases. Am J Surg.
$1952 ; 83: 161$

16. Cantürk Z, Sentürk O, Cantürk NZ, et al. Prevalence and risk factors for gall bladder polyps. East Afr Med J. 2007;84:336-41.

17. Lee JK, Hahn SJ, Kang HW, et al. Visceral Obesity If Associated with Gallbladder Polyps. Gut Liver. 2016;10(1):133-139. doi: 10.5009/gnl14506.

18. Gallahan WC, Conway JD. Diagnosis and management of gallbladder polyps. Gastroenterol Clin North Am. 2010;39:359-367.

19. Lee KF, Wong J, Li JC, Lai PB. Polypoid lesions of the gallbladder. Am J Surg. 2004;188:186-190.

20. Cha $\mathrm{BH}, \mathrm{H}$ wang $\mathrm{JH}$, Lee $\mathrm{SH}$, et al. Pre-operative factors that can predict neoplastic polypoid lesions of the gallbladder. World J Gastroenterol. 2011;17:2216-22.

21. Wiles R, Thoeni RF, Barbu ST, et al. Management and follow-up of gallbladder polyps. Eur Radiol. 2017;1-1. doi: 10.1007/s00330-017-4742-y

22. Koga A, Watanabe K, Fukuyama $T$, et al. Diagnosis and operative indications for polypoid lesions of the gallbladder. Arch Surg. 1988;123(1):26-9.

23. Ishikawa $\mathrm{O}$, Ohhigashi $\mathrm{H}$, Imaoka $\mathrm{S}$, et al. The difference in malignancy between pedunculated and sessile polypoid lesions of the gallbladder. Am J Gastroenterol. 1989;84(11):1386-90.

24. Marangoni G, Hakeem A, Toogood GJ, et al. Treatment and surveillance of polypoid lesions of the gallbladder in the United Kingdom. HPB (Oxford). 2012;14:435-440.

25. Akyürek N, Salman B, Irkörücü $O$, et al. Ultrasonography in the diagnosis of true gallbladder polyps: the contradiction in the literature. HPB (Oxford). 2005;7(2):155-158. doi: 10.1080/13651820510003762.

26. Zielinski MD, Atwell TD, Davis PW, et al. Comparison of surgically resected polypoid lesions of the gallbladder to their pre-operative ultrasound characteristics. J Gastrointest Surg. 2009;13(1):19-25. doi: 10.1007/s11605-008-0725-2.

27. Numata $K$, Oka $H$, Morimoto $M$, et al. Differential diagnosis of gallbladder diseases with contrast-enhanced harmonic gray scale ultrasonography. J Ultrasound Med. 2007;26:763-774.

28. Jang JY, Kim SW, Lee SE, et al. Differential diagnostic and staging accuracies of high resolution ultrasonography, endoscopic ultrasonography, and multidetector computed tomography for gallbladder polypoid lesions and gallbladder cancer. Ann Surg. 2009;250:943-9.

\section{PEER REVIEW}

Not commissioned. Externally peer reviewed. 


\section{CONFLICTS OF INTEREST}

The authors declare that they have no competing interests.

\section{FUNDING}

None

\section{ETHICS COMMITTEE APPROVAL}

This research has been approved by Jordan University of science and technology research committee, with an approval reference number of [477-2017].

Table 1: Patients' clinical and histopathologic (polyps) features

\begin{tabular}{|l|l|}
\hline Age in years (mean, range) & $54(17-85)$ \\
\hline Sex & $31 \mathrm{~F}(67.4 \%)$ \\
\hline Female & $31(66.0 \%)$ \\
\hline Male & $16(34.0 \%)$ \\
\hline Body mass index $\left(\mathrm{Kg} / \mathrm{m}^{2}\right)$ & $30(19-43)$ \\
\hline Number of Polyps (by histopathology) \\
\hline Single & $29(63.0 \%)$ \\
\hline Multiple & $17(37.0 \%)$ \\
\hline Polyp sizes in cm (mean, range) & $1.0(0.2-2.2)$ \\
\hline $\begin{array}{l}\text { Total polyps detected by ultrasound out of } \\
\text { 46 polyps }\end{array}$ & $9(19.5 \%)$ \\
\hline Histology & \multicolumn{2}{|l}{} \\
\hline Adenocarcinoma & $5(10.9 \%)$ \\
\hline Adenoma & $4(8.7 \%)$ \\
\hline Adenomyoma & $6(13 \%)$ \\
\hline Cholesterol polyps & $13(28.3 \%)$ \\
\hline Hyperplastic polyps & $18(39.1 \%)$ \\
\hline Chronic cholecystitis & $40(87.0 \%)$ \\
\hline
\end{tabular}

* 37/46 (80\%) GBPs were diagnosed as stones by ultrasound

Figure 1: Hyperplastic gallbladder polyp

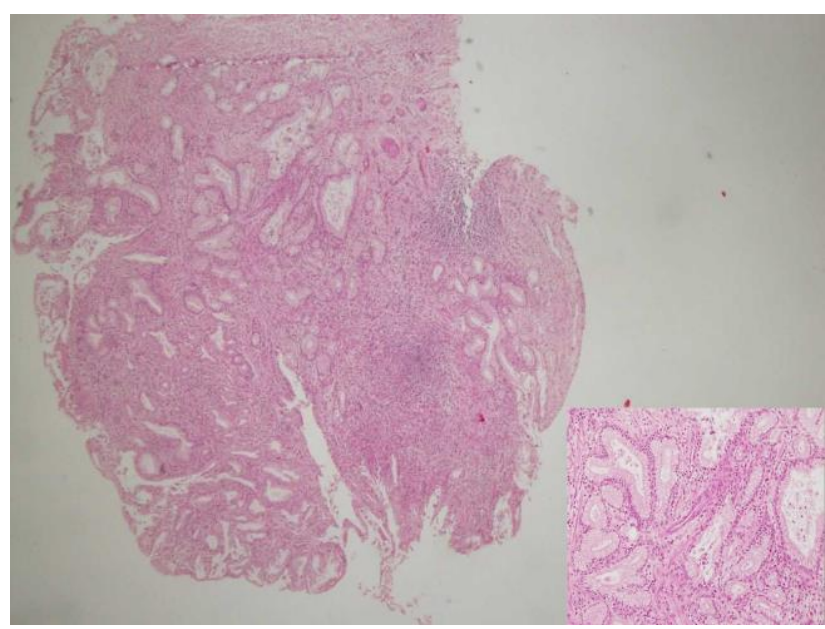

\section{Figure 2: Adenomatous gallbladder polyp (adenoma)}

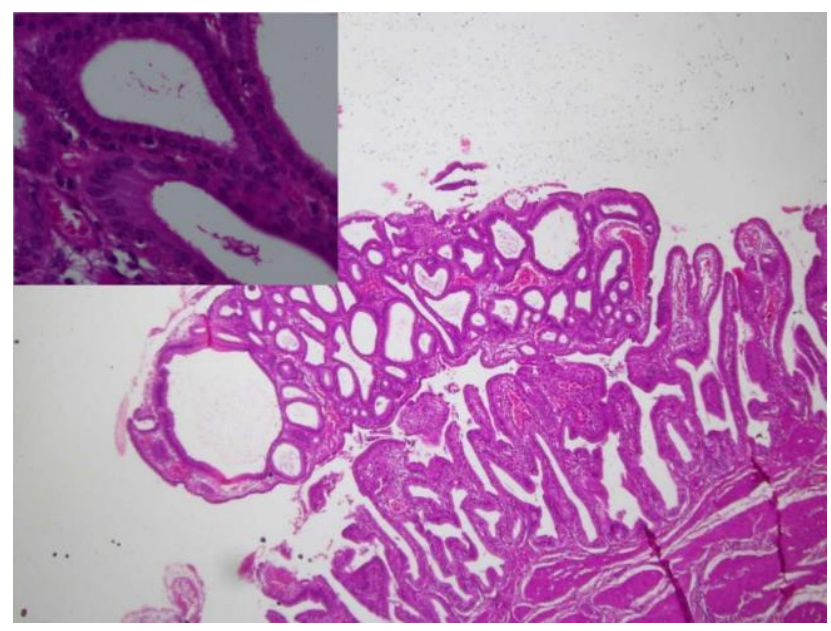

